\title{
Ionizing Radiation Increases the Circulatory Endothelial Progenitor Cell Population in Glottic Cancer Patients
}

\author{
Sayantan Bhattacharyya ${ }^{1}$, Tapas Maji ${ }^{2}$, Dilip Kumar Ray ${ }^{2}$, Anup Kumar Bhowmick ${ }^{3}$ and Nabendu Murmu ${ }^{1^{*}}$ \\ ${ }^{1}$ Department of Signal Transduction and Biogenic Amines, Chittaranjan National Cancer Institute, 37-S.P Mukherjee Road, Kolkata-700026, India \\ ${ }^{2}$ Department of Radiation Oncology, Chittaranjan National Cancer Institute, 37-S.P Mukherjee Road, Kolkata-700026, India \\ ${ }^{3}$ Department of ENT, Chittaranjan National Cancer Institute, 37-S.P Mukherjee Road, Kolkata-700026, India
}

*Corresponding author: Nabendu Murmu, Department of Signal Transduction and Biogenic Amines, Chittaranjan National Cancer Institute, 37, S.P. Mukherjee Road, Kolkata-700026, West Bengal, India, Tel: 9133-2476-5101, extn. 324; Fax: 9133-2475-7606; E-mail: nabendu.murmu@cnci.org.in

Received date: Aug 16, 2015, Accepted date: Sep 14, 2015, Publication date: Sep 18, 2015

Copyright: (c) 2015 Bhattacharyya S, et al. This is an open-access article distributed under the terms of the Creative Commons Attribution License; which permits unrestricted use; distribution; and reproduction in any medium; provided the original author and source are credited.

\begin{abstract}
Background: Cancer of the throat or larynx is one of the predominant cancer types in India and Intensity Mediated Radiation Therapy (IMRT) is the most crucial treatment regimen against the disease. We aimed to examine the effect of Circulating Endothelial Progenitor (CEP) cells in Laryngeal cancer patients undergoing radiation therapy.

Patients: Five Laryngeal cancer patients were selected for the work. All patients were suffering from Squamous Cell Carcinoma (SCC) of the glottis and admitted to the institute with CT1 and CT2 stage of tumor with no lymph node metastasis $\left(\mathrm{CN}_{0}\right)$. After thorough check up the patients were subjected to conventional mononodal radiotherapy (IMRT), fractionated doses to the highest dose (1.8-2 Gy per fraction). Peripheral Blood Mononuclear Cells (PBMC) was isolated from all 5 patients and flow cytometric analysis (using anti CD 44 and CD309 monoclonal antibody) was performed before and after completion of the entire course.
\end{abstract}

Results: Results showed upregulation of the CEPs in all cases after exposure to radiotherapy. Additional immunofluorescence staining confirmed the rapid increase of these cells indicating a strong correlation between the exposure to ionizing radiation and stem cell expression in patients suffering from Glottic cancer.

Conclusion: Increase in the CEPs suggests that the tissue damage due to radiation exposure activate the stem cell niche and allures CEPs in the peripheral blood for angiogenesis. Further prospective assessments are warranted.

Keywords: Glottic cancer; Circulating endothelial progenitors; Intensity mediated radiation therapy

\section{Introduction}

The annual incidence of head and neck cancers worldwide is more than 550,000 cases with around 300,000 deaths each year [1]. Male to female ratio ranges from 2:1 to 4:1. About $90 \%$ of all head and neck cancers are squamous cell carcinomas (HNSCC). According to the American Cancer Society, about 13,560 new cases of laryngeal cancer $(10,720$ in men and 2,840 in women) has been documented in United States so far in 2015 (2014 Copyright American Cancer Society).

In the past decade, researchers have gained significant insights on the role of bone marrow (BM)-derived cells in adult neovascularization. A subset of BM-derived cells, called circulatory endothelial progenitor cells (CEPs), has been of particular interest, as these cells were suggested to home to sites of neovascularization and neoendothelialization and differentiate into endothelial cells (ECs) in situ, a process referred to as postnatal vasculogenesis. Therefore, EPCs were proposed as a potential regenerative tool for treating human vascular disease and a possible target to confine vessel growth in tumour pathology.
However, conflicting results have been reported in the field, and the identification, characterization, and exact role of EPCs in vascular biology is still a subject of much discussion. CEPs can be subdivided into two main categories, hematopoietic lineage CEPs and nonhematopoietic lineage CEPs. The hematopoietic CEPs originate from $\mathrm{BM}$ and represent a subpopulation of hematopoietic stem cells (HSCs) [2-6].

The hematopoietic CEPs can enter circulation on stimulation as cellular components of blood, negotiating a possibly heterogeneous cell population, represented by, for example, colony forming CEPs, noncolonyforming "differentiating" CEPs, myeloid CEPs, or angiogenic cells.

The nonhematopoietic CEPs are not HSC derivedcells, which can be isolated from blood or tissue samples via the help of sequential culture and distinguished by their rather obvious embryonic cells (EC)-like phenotype [7] or differentiation capability into EC (-like) phenotype [8]. The origin of nonhematopoietic CEPs remains to be clarified, but they are generally thought to be derived from nonhematopoietic tissue prone lineage stem cells or organ blood vessels but not likely from HSC [9].

Another major problem with CEPs was its identification. Several literature has documented various markers for CEPs including CD133, 
Page 2 of 4

CDKDR, CD3, CD19, CD33 etc. However, there is still controversy on choosing the marker while working with CEPs. In our study we chose two different receptor markers for identification of CEPs-CD44 which is a well-known marker for stem cells as CEPs show stemness and Flk-1, which is type-II receptor for Vascular Endothelial Growth Factor (VEGFR-II), a protein expressed in endothelial cells through which vasculogenesis as well as angiogenesis occurs.

Previous works of Brunners et al. showed that Head and Neck Cancer patients show elevated level of EPCs whereas there was no alteration in Circulating Endothelial Cells (CECs) - endothelial cells that have been shed from the lining of the vascular wall into the blood stream [10].

In another study, Plaumbo et al. showed that radioiodine therapy causes temporary fall in CEP count [11]. When it comes to the treatment regimen, the most frequent tool for treating Glottic cancer is still radiotherapy at a dose range of 65-75 Gy, the highest range of radiation dose among all types of cancers. In this pilot study, we tried to examine the alteration in the CEP count present in peripheral blood of Glottic cancer patients undergoing radiotherapy.

\section{Patient Samples}

5 Patients undergoing IMRT (60 Gy, 2 Gy fractions) in Chittaranjan National Cancer Institute (CNCI), Kolkata, India, were screened from April, 2014 to March, 2015, and demographic details for all patients including age, sex, and personal history about smoking were recorded. All blood samples were collected on the day radiation treatment started (for pre-treatment) and after one week of completion of total radiotherapy cycle (for post-treatment).

All tumors were histopathologically categorized as squamous cell carcinoma of the glottis. Patients with recurrent glottic tumor and other types of laryngeal cancer (i.e., verrucous, sarcomatoid, and lymphoepithelial carcinoma) were excluded from the study. All works described here had been carried out in accordance with The Code of Ethics of the World Medical Association. (Declaration of Helsinki) and after getting formal consent from each patient.

\begin{tabular}{|c|c|c|c|c|}
\hline Patient ID & Age (Years) & Sex & TNM Stage & $\begin{array}{l}\text { Treatment } \\
\text { Regimen }\end{array}$ \\
\hline P1 & 63 & Male & CT1N0Mx & $\begin{array}{l}\text { IMRT } \\
\left(\begin{array}{l}60 \mathrm{~Gy}, \quad 30 \\
\text { cycles) }\end{array}\right.\end{array}$ \\
\hline P2 & 56 & Male & CT2NOMx & $\begin{array}{l}\text { IMRT } \\
\text { (66 Gy, } 33 \\
\text { cycles) }\end{array}$ \\
\hline P3 & 50 & Male & CT1N0Mx & $\begin{array}{l}\text { IMRT } \\
\left(\begin{array}{l}60 \mathrm{~Gy}, \quad 30 \\
\text { cycles) }\end{array}\right.\end{array}$ \\
\hline P4 & 66 & Male & CT2NOMx & $\begin{array}{l}\text { IMRT } \\
\text { (66 Gy, } 33 \\
\text { cycles) }\end{array}$ \\
\hline P5 & 67 & Male & CT2NOMx & $\begin{array}{l}\text { IMRT } \\
\text { (66 Gy, } 33 \\
\text { cycles) }\end{array}$ \\
\hline
\end{tabular}

\section{Flow cytometric analysis}

PBMCs were isolated from the whole blood by Ficoll density gradient centrifugation. The peripheral blood was mixed with $1 \mathrm{X}$ Phosphate Buffer Saline (PBS) and the mixture was put dropwise on Ficoll in 4:3 ratios.

The samples were next centrifuged in $900 \mathrm{rpm}$ for 30 minutes in a fixed angle rotor at room temperature and PBMCs were carefully collected from the buffy coat. $0.3 \times 10^{6}$ cells were taken for each experiment and after thorough washing using PBS; the cells were incubated with PE tagged anti CD $44(\mathrm{ScBt})$ and FITC tagged anti Flk-1 antibodies (ScBt). After proper fixation with paraformaldehyde, the enumeration of CEP count was acquired using BD FACSCalibur Flow Cytometer.

\section{Immunofluorescence staining}

The PBMC suspension was poured on a slide $(100 \mu \mathrm{l})$ and fixed with Methanol for 15 minutes. Once fixation was done, cells were incubated with rabbit polyclonal antibody against CD 44 and Flk-1 (1:600 dilutions, $\mathrm{ScBt}$ ) for 1 hour at room temperature.

FITC conjugated secondary rabbit polyclonal antibody (1:800 dilutions) were used and incubated at room temperature for 45 minutes. Diaminidophenylindole (DAPI) was used for the nuclear staining and mounting. The cells were imaged under fluorescence microscope (Leica DM4000 B, Germany).

\section{Result}

Results showed marked upregulation in CD 44 and Flk-1 expression in all cases after completion of radiotherapy (Figure 1). When compared, the patients' pre-treatment status for CEPs increased almost up to 1.5 fold.

Surprisingly when the expression status of CD 44 and Flk-1 was examined in the monocyte population, post-radiation parameters showed slight decrease in those proteins' expression (Figure 2). Immunofluorescence staining clearly showed positive expression for CD 44 as well as Flk-1 in the PBMCs (Figure 3).

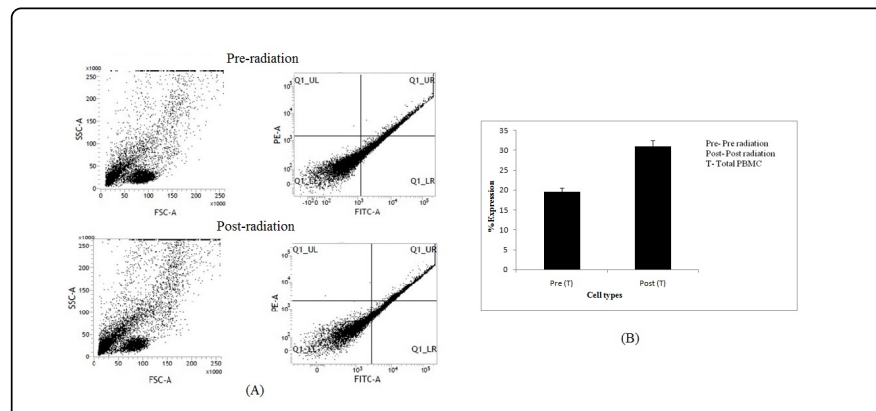

Figure 1: Flow cytometric analysis showing altered expression in CD 44- Flk-1 double positive quadrant (UR) after radiation treatment in total PBMC (A). Graphical representation showing increase in CEP population by $11 \%$. 


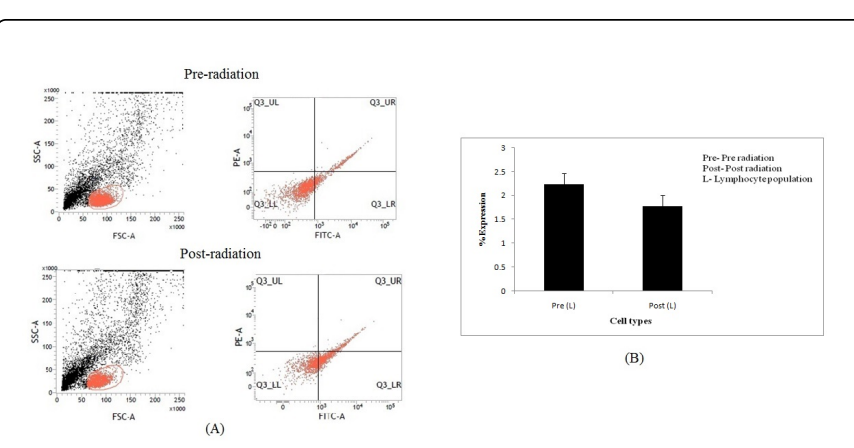

Figure 2: Flow cytometric analysis showing altered expression in the CEP marker (CD 44-Flk-1) quadrant (UR) after radiation treatment in the lymphocyte population (A). Graphical representation showing decrease in CEP population by $1 \%$.

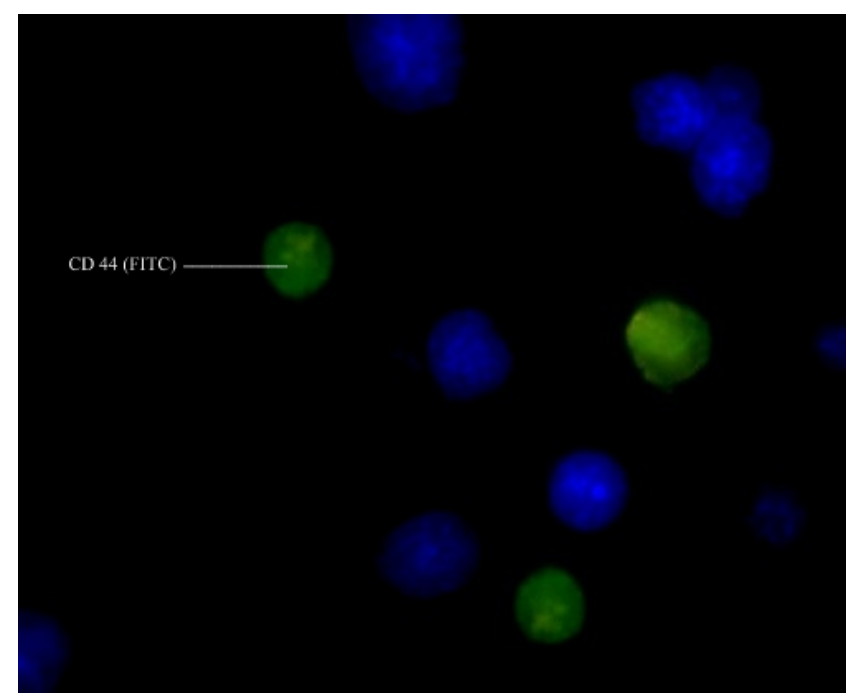

Figure 3: Immunofluorescence staining showing positive expression for CD 44 (Green) in the PBMC population. The nucleus is stained with DAPI (Blue).

\section{Discussion}

Recent study suggests that endothelial cells are the principal target of radiation injury in the intestinal mucosa and elsewhere [12,13]. Apoptosis of endothelial cells in the microvasculature occurs first, whereas death of neighboring epithelial cells is a secondary event leading to clinical symptoms associated with mucositis, colitis, and other organ toxicities. Although radiotherapy is known to reduce the pool of hematopoietic stem cells [14], so far, there have been only a few clinical reports on the detection of circulating CEPs and most of these studies have evaluated the significance of CEPs in non-cancer conditions [15-17]. The significance of circulating CEPs in cancers has been reported in case of multiple myeloma $[18,19]$.

Recent studies have also demonstrated that the number of CEPs in the peripheral blood of cancer patients is altered by disease status and treatment, such as chemotherapy and anti-angiogenic therapies [20]. Accordingly, a potential value of CEPs as biomarker in the disease course and responses to newly introduced chemotherapeutic drugs is increasingly being discussed. Recently, a series of investigations have suggested that endothelial progenitor cells (CEPs) derived from the bone marrow are present in peripheral blood and these cells get recruited to denuded areas for incorporation into the nascent endothelium [21,22]. New therapies targeting to induce these progenitor cells, which are fundamental to radiation induced injury repair, can significantly improve clinical treatment of cancer. Therefore, it is of paramount importance to identify subpopulations of cells exhibiting stem marker expression and behavior. Our study showed that Glottic cancer patients undergoing IMRT has an increased amount of CEPs as response to radiation which may be used as a marker for further characterization of the disease.

\section{Conflict of Interest}

The authors have declared no conflict of interest exists.

\section{Acknowledgement}

We would like to express our gratitude to Prof. (Dr.) Jaydip Biswas, Director, CNCI for his support throughout the entire work. We are also thankful to the Department of Science and Technology (DST), India for funding the project.

\section{References}

1. Jemal A, Bray F, Center MM, Ferlay J, Ward E, et al. (2011) Global cancer statistics. CA Cancer J Clin 61: 69-90.

2. Jemal A, Siegel R, Ward E, Murray T, Xu J, et al. (2007) Cancer statistics, 2007. CA Cancer J Clin 57: 43-66.

3. Boyle P, Levin B (2008) World Cancer Report 2008. International Agency for Research on Cancer.

4. Bailey AS, Jiang S, Afentoulis M, Baumann CI, Schroeder DA, et al. (2004) Transplanted adult hematopoietic stems cells differentiate into functional endothelial cells. Blood 103: 13-19.

5. Pelosi E, Valtieri M, Coppola S, Botta R, Gabbianelli M, et al. (2002) Identification of the hemangioblast in postnatal life. Blood 100: 3203-3208.

6. Grant MB, May WS, Caballero S, Brown GA, Guthrie SM, et al. (2002) Adult hematopoietic stem cells provide functional hemangioblast activity during retinal neovascularization. Nat Med 8: 607-612.

7. Ingram DA, Caplice NM, Yoder MC (2005) Unresolved questions, changing definitions, and novel paradigms for defining endothelial progenitor cells. Blood 106: 1525-1531.

8. Aicher A, Rentsch M, Sasaki K, Ellwart JW, Fändrich F, et al. (2007) Nonbone marrow-derived circulating progenitor cells contribute to postnatal neovascularization following tissue ischemia. Circ Res 100: 581-589.

9. Timmermans F, Van Hauwermeiren F, De Smedt M, Raedt R, Plasschaert F, et al. (2007) Endothelial outgrowth cells are not derived from CD133+ cells or CD45+ hematopoietic precursors. Arterioscler Thromb Vasc Biol 27: 1572-1579.

10. Brunner M, Thurnher D, Heiduschka G, Grasl MCh, Brostjan C, et al. (2008) Elevated levels of circulating endothelial progenitor cells in head and neck cancer patients. J Surg Oncol 98: 545-550.

11. Palumbo B, Palumbo R, Sinzinger H (2003) Radioidine therapy temporarily increases circulating endothelial cells and decreases endothelial progenitor cells. Nucl Med Rev Cent East Eur 6: 123-126.

12. Paris F, Fuks Z, Kang A, Capodieci P, Juan G, et al. (2001) Endothelial apoptosis as the primary lesion initiating intestinal radiation damage in mice. Science 293: 293-297. 
Citation: Bhattacharyya S, Maji T, Ray DK, Bhowmick AK, Murmu N (2015) Ionizing Radiation Increases the Circulatory Endothelial Progenitor Cell Population in Glottic Cancer Patients. J Nucl Med Radiat Ther 6: 251. doi:10.4172/2155-9619.1000251

Page 4 of 4

13. Garcia-Barros M, Paris F, Cordon-Cardo C, Lyden D, Rafii S, et al. (2003) Tumor response to radiotherapy regulated by endothelial cell apoptosis. Science 300: 1155-1159.

14. Laukkanen MO, Kuramoto K, Calmels B, Takatoku M, von Kalle C, et al (2005) Low-dose total body irradiation causes clonal fluctuation of primate hematopoietic stem and progenitor cells. Blood 105: 1010-1015.

15. Shintani S, Murohara T, Ikeda H, Ueno T, Honma T, et al. (2001) Mobilization of endothelial progenitor cells in patients with acute myocardial infarction. Circulation 103: 2776-2779.

16. Vasa M, Fichtlscherer S, Adler K, Aicher A, Martin H, et al. (2001) Increase in circulating endothelial progenitor cells by statin therapy in patients with stable coronary artery disease. Circulation 103: 2885-2890.

17. Gill M, Dias S, Hattori K, Rivera ML, Hicklin D, et al. (2001) Vascular trauma induces rapid but transient mobilization of VEGFR2(+)AC133(+) endothelial precursor cells. Circ Res 88: 167-174.
18. Kim HK, Song KS, Kim HO, Chung JH, Lee KR, et al. (2003) Circulating numbers of endothelial progenitor cells in patients with gastric and breast cancer. Cancer Lett 198: 83-88.

19. Zhang H, Vakil V, Braunstein M, Smith EL, Maroney J, et al. (2005) Circulating endothelial progenitor cells in multiple myeloma: implications and significance. Blood 105: 3286-3294.

20. Mancuso P, Burlini A, Pruneri G, Goldhirsch A, Martinelli G, et al. (2001) Resting and activated endothelial cells are increased in the peripheral blood of cancer patients. Blood 97: 3658-3661.

21. Asahara T, Murohara T, Sullivan A, Silver M, van der Zee R, et al. (1997) Isolation of putative progenitor endothelial cells for angiogenesis. Science 275: 964-967.

22. Shi Q, Rafii S, Wu MH, Wijelath ES, Yu C, et al. (1998) Evidence for circulating bone marrow-derived endothelial cells. Blood 92: 362-367. 